\title{
Scanning electron microscopic study on the mouthparts of Apis florea (Hymenoptera: Apidae)
}

\author{
Rajeev Kumar, Neelima R. Kumar \\ Department of Zoology, Panjab University, Chandigarh 160014, India
}

Received 29 July 2015 - Revised 24 November 2015 - Accepted 8 December 2015

\begin{abstract}
The present study was undertaken to examine sensory structures on the mouthparts in Apis florea Fabricius (1787) from north western region (India) using scanning electron microscopy. Ultra morphological details revealed that mouthparts of the dwarf honey bees were studded with different sensory structures including sensilla chaetica (A, B and C); sensilla basiconica; sensilla trichodea C; nodulated-form sensilla trichodea C; hair membrane plate sensilla; branched processes and cuticular plate sensilla, which made the organism efficient in forage detection and collection. Sensilla chaetica were found on prementum, galea, labial palps and the glossa and made flow of liquid food to the buccal cavity convenient. Sensilla basiconica were found on labial palps and served probably as a thermoreceptor and hygroreceptor. Cuticular plate sensilla on labial palps and hair membrane plate sensilla found on galea may serve to adjust the segments of the organ and act as mechanoreceptors. The identification and analysis of the distribution of various types of sensilla on the tongue of $A$. florea should be helpful when addressing questions on the ecological and systematic characterisation of the species in future investigations.
\end{abstract}

\section{Apis florea / honey bee / scanning electron microscopy / sensilla / mouthparts}

\section{INTRODUCTION}

Apis florea is commonly called the dwarf honey bee as it is the smallest of all the honey bee species. It is small in terms of worker body size and nest size. It is not ferocious like the other open nesting honey bee (Apis dorsata) but makes a defensive attack when there is some movement around its nest. It nests in the open and makes a single comb, hanging from slender branches of trees or shrubs covered with relatively dense foliage. Nests are usually up to $4 \mathrm{~m}$ above the ground and honey containing cells surround the support from all sides. Combs of the dwarf honey bee are covered with layers of workers bees clinging to each other. In order to protect the nest from ant attacks, worker bees coat both ends of the nest

Corresponding author: N. Kumar, neelimark6@gmail.com

Manuscript editor: Klaus Hartfelder support with sticky strips of propolis or plant resins up to a width of 2.5 to $4 \mathrm{~cm}$. A. florea is the only honey bee species that uses this defensive technique. The dwarf bees perform short forage flights which are often to a distance of $750 \mathrm{~m}$ so that the honey stored by this bee is generally of rather uniform composition. In spite of its small size, the pollinating efficiency of this bee species has been proven to be of high potential in maintaining ecological balance.

The mouth parts of $A$. florea, such as galea, labial palps, glossa and flabellum, bear sensory structures which are adapted for a chewing and lapping method of feeding. A well-developed sensory system is pivotal for the honey bee to locate forage and identify and exploit these resources. Hence, various sensory structures are present on the mouth parts of $A$. florea which may affect the foraging behaviour of the insect. Descriptions of these sensory structures based on their appearance and function have previously been given by 
different authors and attempts have been made to relate these with biological (Wongsiri et al. 1996), behavioural (Free and Williams 1979, Free 1981) and biometric (Hepburn and Hepburn 2005) parameter in order to study ecological variations in honey bees (Hölldobler and Wilson 1990; Michener 1974).

Based on age and physiological maturation, different tasks like comb construction, nursing, nourishing, guarding and foraging are performed by worker honey bees (Lindauer 1952; Michener 1974; Johnson 2010) and most of these functions are associated with mouth parts. Studies on task specialisation, especially in foragers of Apis mellifera have shown that specialisation is associated with differences in sensory thresholds for sucrose, odours and light (Scheiner et al. 2004; Page et al. 2009; Rivera 2009; Scheiner and Erber 2009). Alternatively, differences in sensitivity may depend on the type, number and size or structure of sensory organs which may in turn vary with body size of the individual honey bee. In bumblebees, for example, the length of antennae affects olfactory sensitivity because longer antennae bear more olfactory sensilla (Spaethe et al. 2007; Mujagic et al. 2010). The same may be true for the tongue of honey bee as different honey bee species are very variable in size. Further, it has been reported that the tongue of honey bee shows high geographic variability in relation to available floral resources (Padilla et al. 2001). Three different honey bee species viz. A. dorsata, A. cerana and A. mellifera were studied by Nayyar (2003) and differentiated on the basis of tongue details. According to this author, the branched processes on the distal margin of the flabellum were similar and were of one type in A. cerana and $A$. mellifera while $A$. dorsata had two types of branched processes differentiating it from the other two species (Nayyar 2003). Sharma (2004) studied the antenna and tongue of $A$. cerana and A. florea from Chandigarh using SEM technique. She (Sharma 2004) reported centre- ward converging rows of hair on glossa of A. florea. Furthermore, in the plains population of $A$. cerana, the middle part of the tongue had an uneven arrangement of hair around a sucking plate, while the A. florea population had evenly arranged hair (Sharma 2004).

Anudeep and Kumar (2012) also described several types of sensilla on prementum, labial palps, galea and glossa and reported differences in form of sensory structures on tongue of A. dorsata from the Nurpur and Jaipur regions of India.

To our knowledge, no previous attempts have been made to identify and connect the type of sensilla and foraging task specialisation in A. florea using electron microscopy. Available previous reports are limited to the role of antennae in olfaction and other sensory tasks in A. florea (Gupta 1992). Scanning electron microscopy of the tongue was shown to offer an advanced diagnostic tool for inferences on possibly adaptive variation to native flora comparing $A$. cerana and $A$. mellifera (Kumar et al. 2014). In the present work, therefore the mouth parts details, especially sensory structures of $A$. florea have been examined with scanning electron microscope and are discussed in relation to their possible function.

\section{MATERIAL AND METHODS}

Dwarf honey bees, Apis florea F., workers were collected from locations in Chandigarh, India. Samples were collected directly from the colonies during the evening. Fifty bees were collected per nest and seven were randomly taken for SEM studies. Worker honey bees were dissected following the protocol of Bálint et al. (2004). The tongue was carefully excised from the sockets with fine forceps under a dissecting microscope and fixed in $5 \%$ glutaraldehyde. After dehydration through a graded series of acetone, the specimens were dried in a critical point drier, mounted on aluminium stubs with double adhesive tape and coated with a thin layer of gold palladium in a vacuum evaporator (JEOL JFC-1600 Auto fine coater). Coated specimens were analysed in a JEOL scanning electron microscope (JEOL JSM 6490) operating at an 
accelerating voltage of $10-25 \mathrm{kV}$ and images were recorded with a digital camera.

\section{RESULTS}

The proboscis of $A$. florea contains appendages for ingestion and the sensory organs necessary for recognising forage compounds. A dorsal view (Figure 1a) of mouth parts showed a pair each of galeae and labial palps and a single glossa terminated by flabellum. A galea was fully visible and covered the first segment of labial palp. The distal three labial segments were also visible. A ventral view (Figure $1 b$ ) of the mouth parts displayed the prementum, a pair of labial palps, a single glossa and the flabellum. The hairy parts of the glossa and flabellum were fully visible.

Postmentum - this was triangular and arrowhead shaped lying just at the base of prementum (Figure 2a). The surface of the postmentum was covered with cuticular scales (CPS) and was free of any other type of sensilla.

Prementum - this is the proximal second segment of tongue (Figure 1b). A glossa, a pair of paraglossae and a pair of labial palps were seen to arise from this segment. A series of parallel and irregular ridges arranged in a concentric manner and opening at the distal end were present (Figure 2a, b).

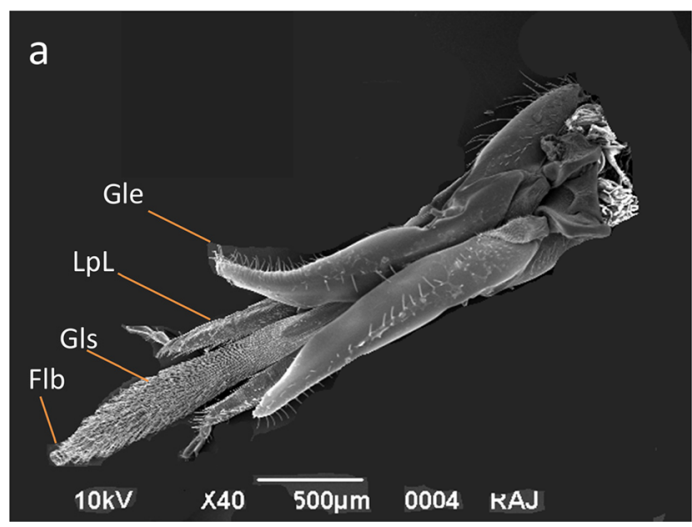

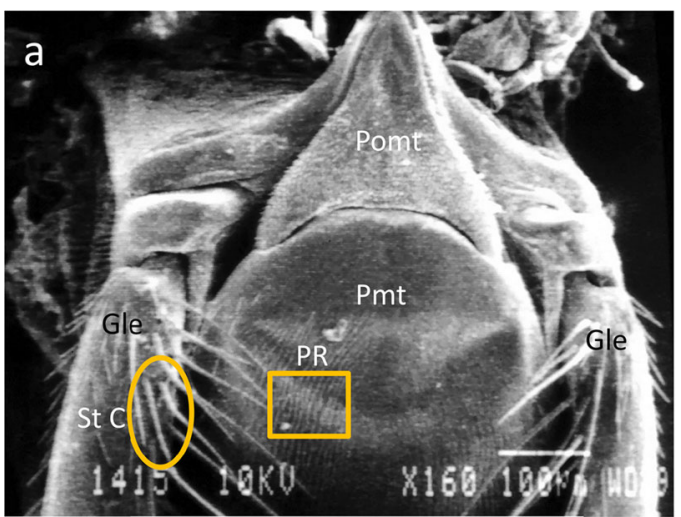

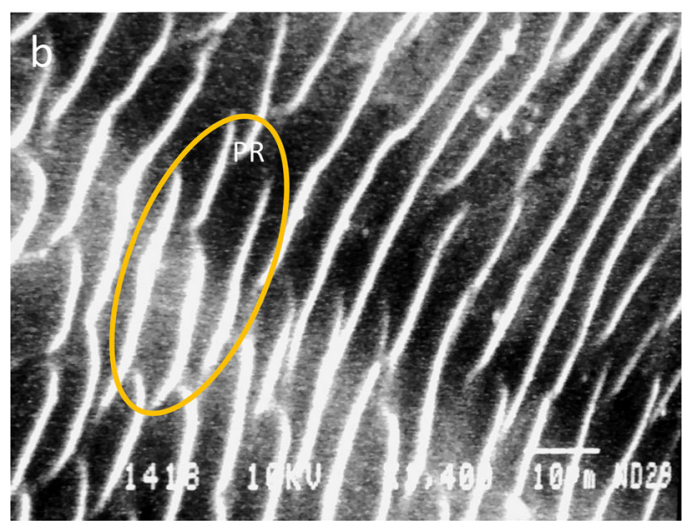

Figure 2. Scanning electron micrographs of tongue of Apis florea in ventral view showing: a postmentum (Pomt), prementum $(P m t)$, parallel ridges $(P R)$ on the prementum, galea (Gle) and sensilla trichodea $\mathrm{C}$ on galea. b Parallel ridges on prementum of $A$. florea .

Glossa - scanning electron microscopic details of the glossa are shown in Figure 3a-d.

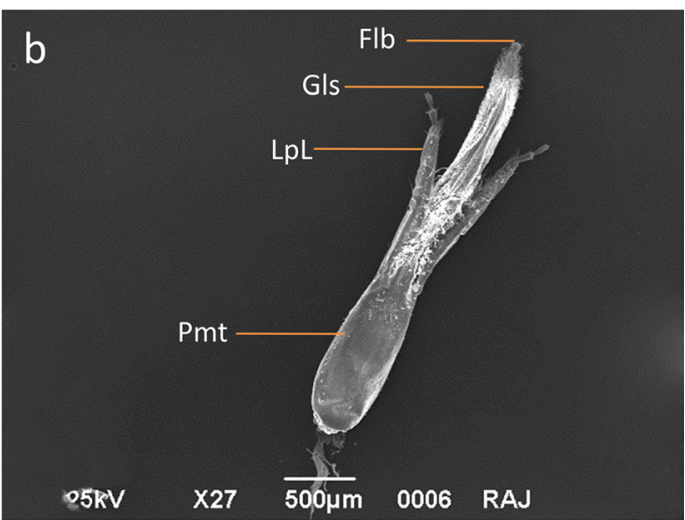

Figure 1. Mouth parts of Apis florea F. a Dorsal view showing galea (Gle), labial palps ( $L p L)$, glossa $(G l s)$ and flabellum $(F l b)$. b Ventral view showing prementum (Pmt), labial palps $(L p L)$, glossa $(G l s)$ and flabellum $(F l b)$. 

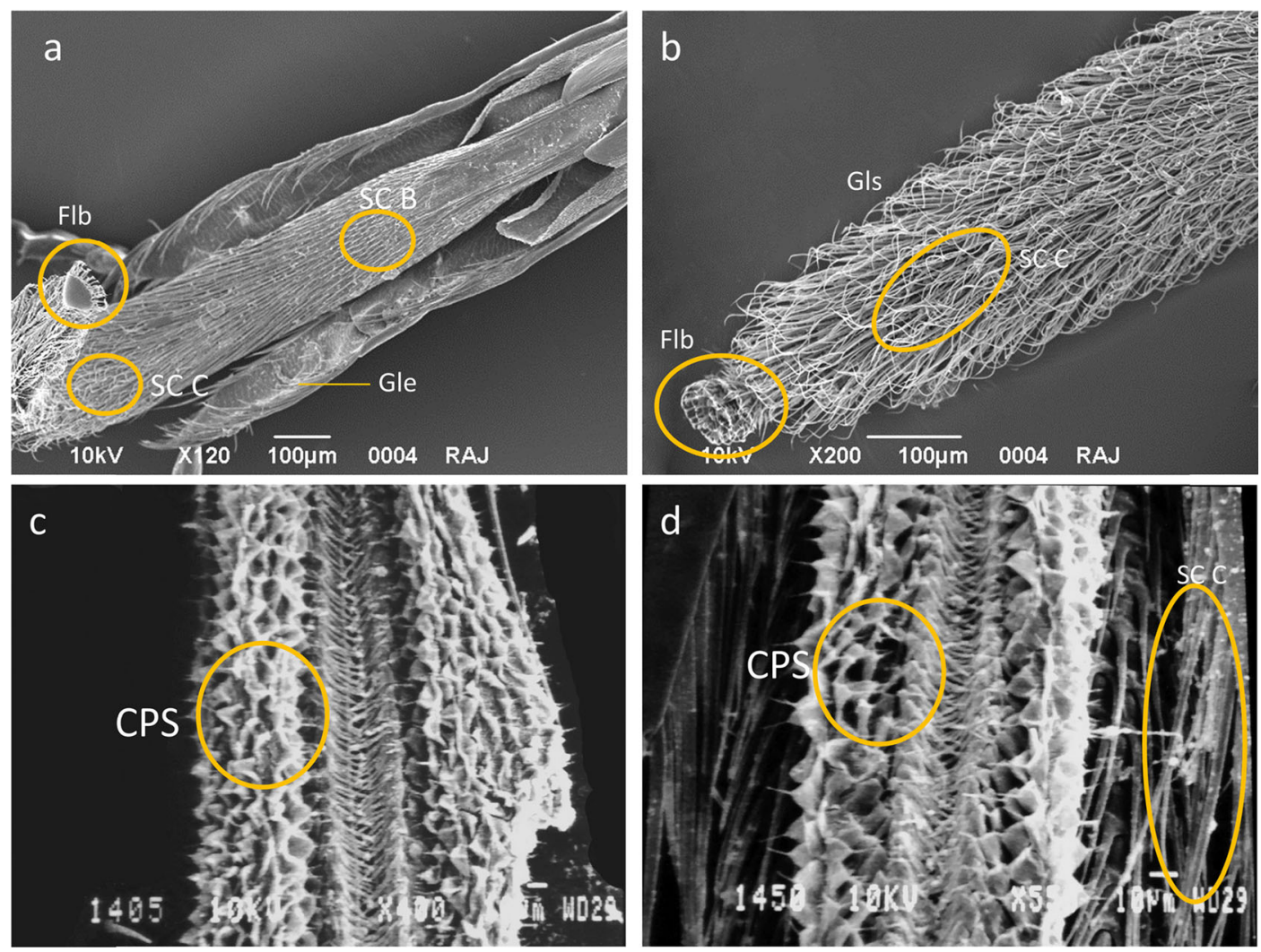

Figure 3. Glossa of $A$. florea a Dorsal view showing sensilla chaetica B $(S C B)$, sensilla chaetica $\mathrm{C}(S C C)$ and ventral view of flabellum $(F l b)$, paraglossa $(P G)$. b Dorsal view showing sensilla chaetica $\mathrm{C}(S C C)$ and flabellum $(F l b)$. c Ventral view showing cuticular plate sensilla (CPS). d Ventral view showing cuticular plate sensilla $(C P S)$ and sensilla chaetica $\mathrm{C}(S C C)$.

It is the most extended appendage of the tongue. At the base of the glossa, a pair of paraglossae which emanated from prementum could be seen (Figure 3a). Four types of sensory structures were identified on the glossa, including sensilla chaetica B and C, cuticular plate sensilla and branched processes. Cuticular plate sensilla were found on the ventral surface of the glossa where they form a channel for the flow of nectar. The sensilla chaetica $\mathrm{C}$ were present on the ventral surface of the tongue where they formed a convergent zone towards the distal end of the glossa (Figure 3c, d). The sensilla chaetica C (SC C) were bent and long and covered the joint between the glossa and flabellum (Figure 4b). Sensilla chaetica A, partially covered by sensilla chaetica $\mathrm{C}$, were characteristically present at the joint of glossa and flabellum (Figure 4a, b).

Flabellum - this is the distal-most part of tongue. It was triangular in shape in A. florea (Figure $4 \mathrm{a}-\mathrm{d}$ ). The margins of the flabellum had long and uniform branched processes (Figure 4b, d) which were characteristically branched into three processes that were inwardly bent (Figure 4a, b, d).

Labial palp —immediately on the lateral side of the glossa was a pair of labial palps. A lateral view of the labial palp displayed three segments with numerous sensilla which probably served as sensors for taste and touch (Figure 5a). Four types of sensilla namely sensilla basiconica, sensilla chaetica A and $\mathrm{C}$ and cuticular plate sensilla were identified on the labial palps of $A$. florea (Figure $5 \mathrm{a}-\mathrm{d}$ ). 

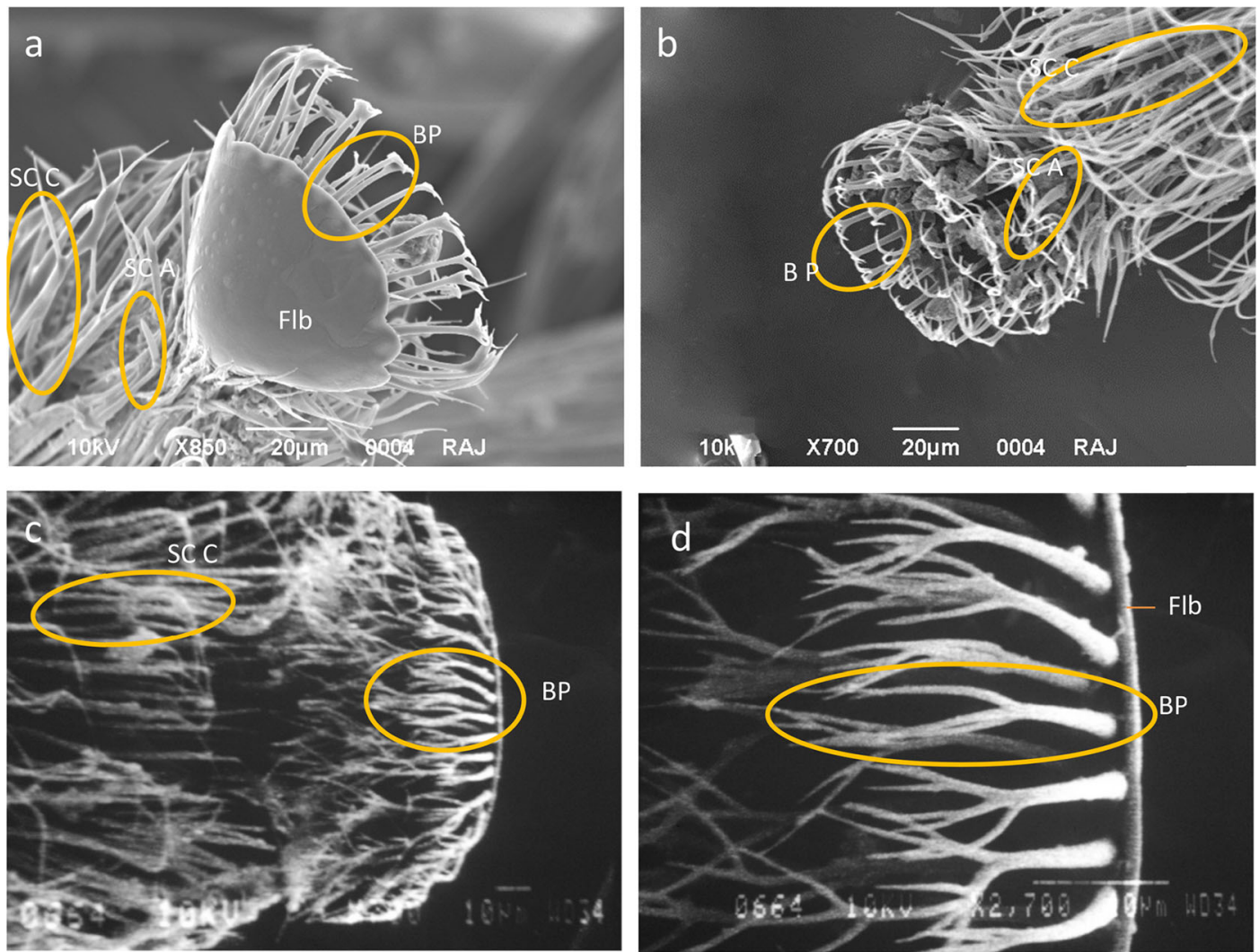

Figure 4. Tongue tip of $A$. florea showing a Flabellum $(F l b)$ in ventral view, branched processes $(B P)$, sensilla chaetica $\mathrm{A}(S C A)$ and sensilla chaetica $\mathrm{C}(S C C)$. b Branched processes $(B P)$ on flabellum and sensilla chaetica $\mathrm{A}$ $(S C A)$ on distal end of glossa. $\mathbf{c}$ Branched processes $(B P)$ on flabellum and sensilla chaetica $\mathrm{C}(S C C)$ on distal end of glossa. d Part of the flabellum $(F l b)$ displaying branched processes $(B P)$.

Sensilla basiconica were found on the distal two segments and were absent from the two proximal segments of the labial palp (Figure 5a, b, d). Sensilla chaetica (SC A) were found on the two terminal segments. These could be distinguished by their curved terminal ends. There were 9-12 sensilla chaetica (SC A) on each segment. SC C were present on the lateral margins of second segment and extended up to the middle of the third labial segment (Figure 5a). A cuticular plate (CP) area was present in the inter labial palp joints and cuticular scales were arranged circumferentially (Figure 5a, b, e).

Galea - the lateral sides of the galea exhibited the presence of unique nodulated sensilla trichodea ( $\mathrm{St} \mathrm{Cn}$ ), sensilla chaetica $\mathrm{C}$ (SC C) (Figure 6a) and sensilla trichodea C (St C) (Figure 2a). An annulated plate was observed at the distal end of this segment (Figure 7a, b). A maxillary palp bearing sensilla was also present on the galea towards its base (Figure $7 \mathrm{a}, \mathrm{c}$ ). The inner part of the galea tip had sensilla chaetica A, B and $\mathrm{C}$ along its margins and cuticular scales on the interior side of the cuticular plate (Figure $7 \mathrm{e}-\mathrm{h}$ ). A single hair membrane plate (HMP) bearing sensilla at the base of each galea was also observed (Figure 7a, d).

Maxilllary palp - this was easily distinguished as a thumb-like segment visible on the lateral margin and base of the galea 

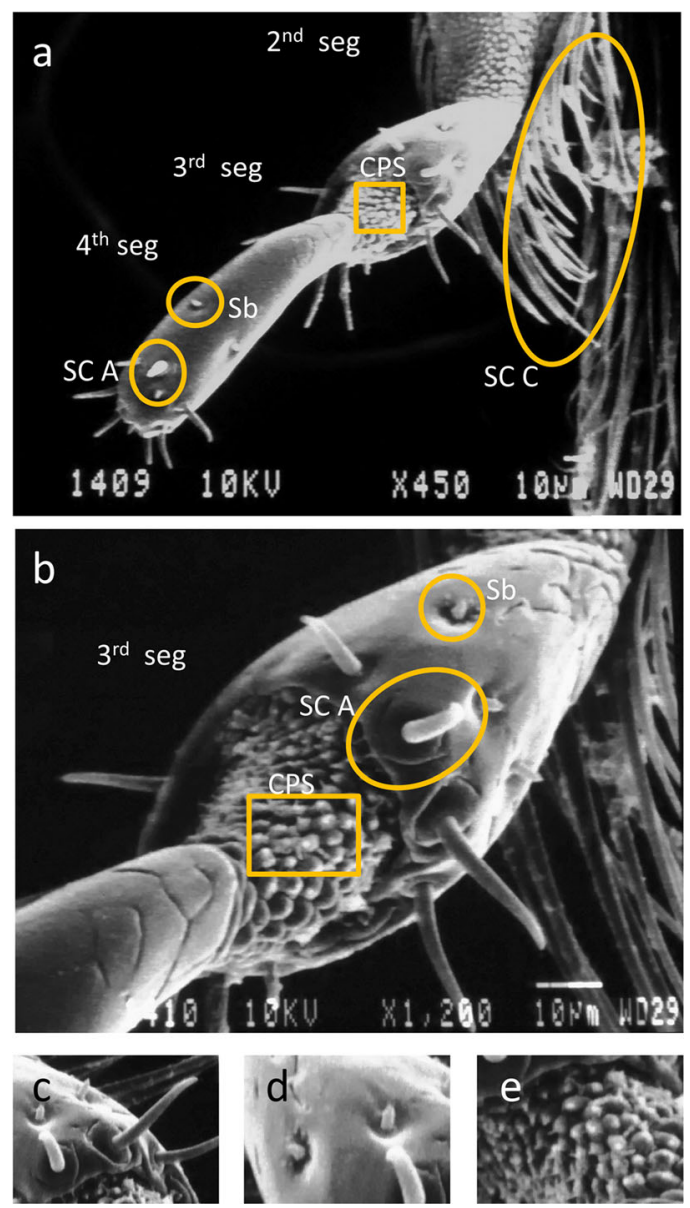

Figure 5. Labial palp of $A$. florea a Lateral view showing second segment (2nd seg), third segment (3rd seg), fourth segment (4th seg), cuticular plate sensilla $(C P S)$, sensilla chaetica $\mathrm{C}(S C C)$, sensilla chaetica A $(S C A)$ and sensilla basiconica $(S b)$. b Lateral view of third segment ( $3 r d$ segment) enlarged to show cuticular plate sensilla $(C P S)$, sensilla chaetica A $(S C A)$ and sensilla basiconica $(S b)$. c Sensilla chaetica A $(S C A)$ on third segment. d Sensilla basiconica $(S b)$ on fourth segment. e Cuticular plate sensilla (CPS) between the third and fourth segment.

(Figures $6 \mathrm{~b}$ and $7 \mathrm{a}, \mathrm{c}$ ). Two forms of sensilla chaetica (types A and B) were observed on it (Figure 6b).

\section{DISCUSSION}

Sensory structures known as sensilla are present on different parts of the bodies of insects.
Some of the well-known sensilla described and classified by previous authors are discussed hereunder:

Sensilla basiconica are straight digitiform, peg or finger-like structures having a porous tip and are located in a shallow depressed socket. On the antenna of the European honey bee A. mellifera, various functions have been attributed to these sensilla such as chemoreceptor (Snodgrass 1956), gustatory (Schneider et al. 1964; Slifer et al. 1959; Lacher 1964; Esslen and Kaissling 1976) and olfactory (Awad et al. 2014). Pe'rez-Gonza'lez and Zaballos (2013) described three types of sensilla basiconica $(\mathrm{Sb})$ on antennae of Typhlocheris. A first type (Sb1) was very short conical structures on the stem of the scape and pedicel and functioned as mechano- or proprioceptors (Merivee et al. 2000, 2002). A second type (Sb2) was a very short, sharply bent sensillum resembling a type of trichoid sensillum which probably served as an olfactory structure. A third type (Sb3) were short conical and hair-like, and their number and distribution varied randomly within the genus. These functioned as mechanoreceptors.

Sensilla trichodea are freely moveable setiform hairs of variable length with generally a proportional diameter with respect to length. They have been ascribed functions such as mechanosensory, chemosensory and thermo sensory; sensitive to touch vibrations, air movements and sound (Erickson et al. 2009) and also touch and taste receptors (Vogel 1921; Frisch 1967; Schneider 1968; Dietz and Humphreys 1971).

Sensilla placodea are peg-like structures placed on top of a conical cuticular style and serve as mechanoreceptors or have olfactory or chemosensory function. These have been reported to function as odour receptors in A. mellifera (Lacher and Schneider 1963; Kaissling and Renner 1968; Schneider and 

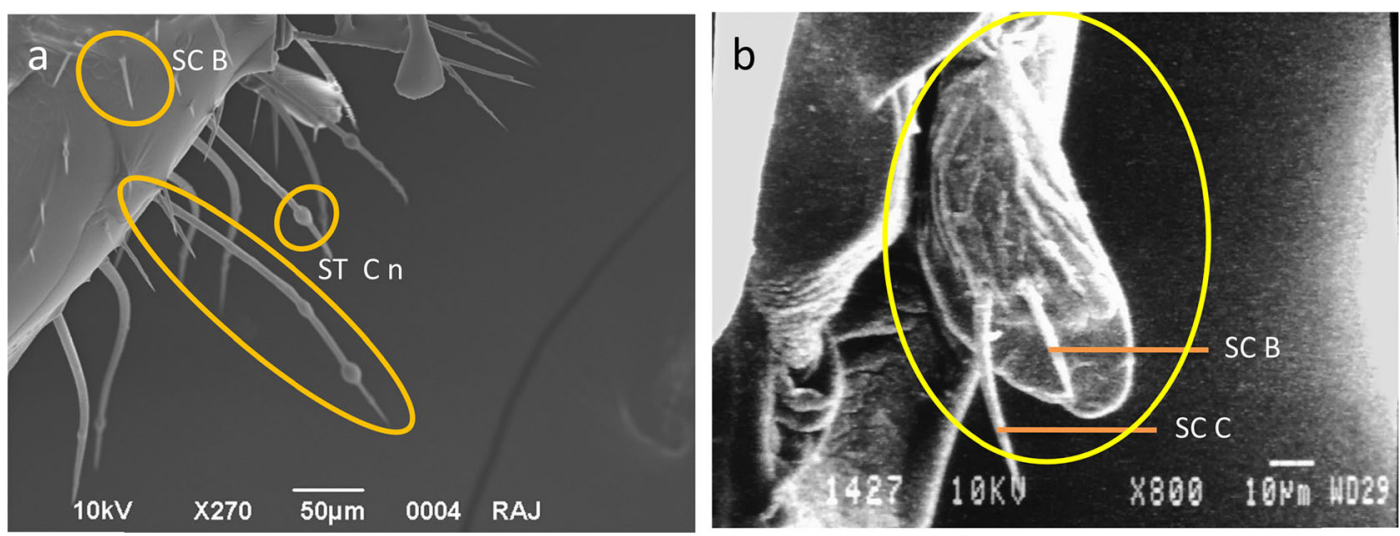

Figure 6. a Base of galea showing sensilla chaetica $\mathrm{B}(S C B)$ and nodulated form of sensilla trichodea $\mathrm{C}(\mathrm{St} \mathrm{Cn})$. b Maxillary palp showing presence of sensilla chaetica $\mathrm{C}(S C C)$ and sensilla chaetica $\mathrm{B}(S C B)$.

Steinbrecht 1968; Agren 1977; Crane 1990) A. dorsata, A. florea and Apis andreniformes (Suwannapong et al. 2012) and as olfactory receptors in A. mellifera (Crane 1990; Gupta 1992).

Sensilla ampullacea consist of a pore surrounded by a smooth surface and are associated with the detection of pheromones, temperature, humidity (Lacher 1964) and changes in concentration of $\mathrm{CO}_{2}$ (Kleineidam et al. 2000).
Sensilla campaniformia have an oval, dome-shaped, flexible cuticular apparatus with a small depression in the centre. It has been reported to function as mechanoreceptor (Zacharuk 1985).

Sensilla chaetica are socketed, stout bristles, sometimes spine-like sharp and tapering with a porous or non porous tip. These sometimes resemble sensilla trichodea except that they have thick cuticular shafts and are not freely moveable. They have been described as
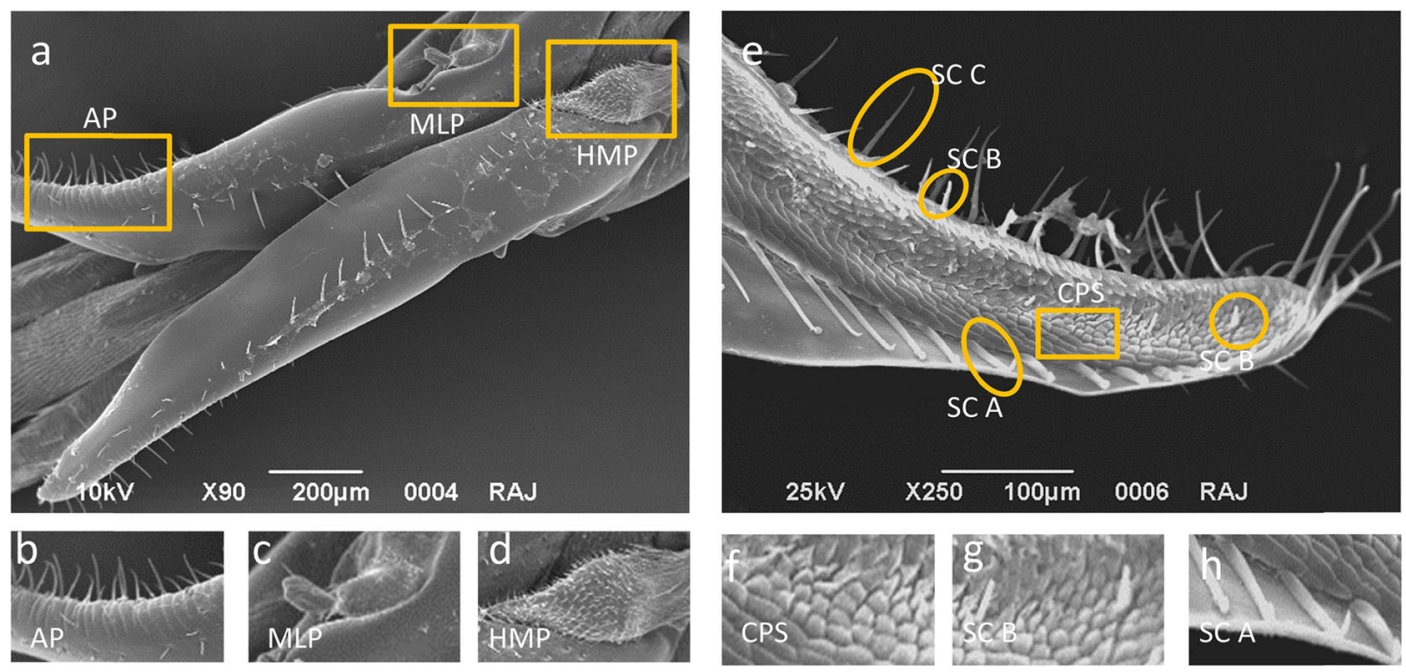

Figure 7. Galea of $A$. florea: a Dorsal view showing maxillary palp $(M L P)$, hair membrane plate $(H M P)$ and annulated plate $(A P)$. b Annulated plate $(A P)$. c Maxillary palp $(M L P)$. d Hair membrane plate $(H M P)$. e Ventral view showing cuticular plate sensilla $(C P S)$, sensilla chaetica $\mathrm{C}(S C C)$, sensilla chaetica $\mathrm{B}(S C B)$ and sensilla chaetica A $(S C A)$. f Cuticular plate sensilla $(C P S)$. g Sensilla chaetica B $(S C B)$. h Sensilla chaetica A $(S C A)$. 
odour receptors in honey bee (Awad et al. 2014). The sensilla chaetica can be divided into long (Chaetica I) and short (Chaetica II) and pored chaetica sensilla and poreless chaetic sensilla. The poreless chaetic sensilla may furthermore be long and short. They are usually considered to have tactile and some chemosensory function. Esslen and Kaissling (1976) reported chaetic and basiconic sensilla as gustatory in function in A. mellifera .

Cuticular scales_-Erickson et al. (2009) observed circumferentially arranged cuticular scales on the inter-segmental surface of the first and second segments of the labial palp in queens of the honey bee, A. mellifera, and referred to these as chemoreceptors and/or mechanoreceptors.

Hair membrane plate sensilla - the hair membrane plate exhibit similarity with the Johnston's organ present on the joint of antenna in the honey bee, A. mellifera (Thurm 1964) and cockroaches, Periplaneta americana (Okada and Toh 2001). The presence of this type of sensilla at the base of galea suggests it to be mechanosensory as in case of antenna of honey bees (Thurm 1964) and cockroach, $P$. americana (Okada and Toh 2000, 2001).

Branched processes-Kumar et al. (2014) reported a fringed structure of branched processes at the distal margin of the flabellum in A. mellifera and A. cerana and suggested that these may make liquid absorption by the flabellum more convenient.

Scanning electron microscopy can be a good tool for studying the biodiversity of bees on the basis of the ultrastructure of various sensilla. According to Frisch (1967), different castes of the honey bees perform different functions in the colony and exhibit distinct external morphologies. There are numerous microscopic structures which are taxonomically important and relate to the ecological adaptation of these species. Hudson (1970) recognised mouthparts as taxonomically important and suitable for scanning electron microscopic characterisation. Different sensilla and their distribution on the tongue of $A$. florea adult workers were studied and reported during the present investigations.

Honey bees have developed a complex system for chemoreception. The whole of the body is studded with various types of sensilla among which olfactory sensilla (sensilla basiconica and sensilla chaetica) are prominent structures. However, with respect to taste perception, the tongue is the principal functional structure. In the present investigation four types of sensilla were reported for adult workers of $A$. florea from Chandigarh in India. Erickson et al. (2009) and Goodman (2003) studied the distribution of sensilla on the labrum, maxillae and mandibles of A. mellifera and reported trichodea and basiconic sensilla as chemosensory receptors on the exterior surface of mandibles and prementum.

Sensilla chaetica similar to those found on the prementum of $A$. florea (Figure 2) during the present study have been described on the tongue of insects by other researchers, and they have been attributed mechanosensory or proprioceptive functions based on their characteristic morphology and location (Esslen and Kaissling 1976, Whitehead and Larsen 1976; Erickson et al. 2009; Fisher 2010; Sanchez 2011; Anudeep 2013).

Erickson et al. (1986) reported the presence of peg organs and trichoid sensilla on the labial palps of honey bees substantiating the present observation. The ultimate segment of the labial palp was reported to be bestowed with numerous sensilla (Erickson et al. 1986) and this was also observed in the present study.

Sensilla chaetica B formed a convergence area on the glossa. Similar findings on arrangement patterns of sensilla on the ventral side of the glossa were also reported by Sharma (2004) on the tongue of A. florea and $A$. cerana. This author also reported that dwarf honey bees had two rows of hair converging towards the centre from the margins as observed in the present study while in A. cerana the middle portion of the tongue exhibited an uneven arrangement of long hairs. The similarity in the arrangement pattern of sensilla could be related to a similar type of forage available in the regions of the study. 
The flabellum was triangular in shape and we hypothesise that morphological variations in the flabellum could be related to depth of nectaries in flowers. The deeper the nectaries of flowers the longer the neck of flabellum of a honey bee's tongue should be. The shape of the flabellum may have got modified accordingly. Nayyar (2003) studied the ultrastructure of the tongue of three species of honey bees, viz. A. dorsata, A. cerana and A. mellifera and reported differences in their flabellum structure. The flabellum of A. dorsata, A. cerana and A. mellifera was oval, rhomboidal and triangular in shape, respectively. The pattern of branched processes was similar in A. cerana and A. mellifera but was different in $A$. dorsata. In the present study on the dwarf honey bee, branched processes were of a single type (Figure 7). Erickson et al. (2009) reported a spoon-like geometry of the flabellum with fringed hair or branched processes at the distal end in A. mellifera. According to Erickson et al. 2009, the branched processes may act as a filter for nectar and serve as gustatoreceptors.

In the present study, the large and uniform branched processes at the margins of the flabellum were evenly arranged which may be an indication of their relation to floral diversity. Typically sensilla with branched type of processes in insects have been suggested to be olfactory in function (Steinbrecht 1984; Hallberg et al. 2003; Kristoffersen et al. 2006; Onagbola and Fadamiro 2008; Onagbola et al. 2009).

In conclusion, the scanning electron microscopic studies on the tongue of $A$. florea lead to infer that different sensory structures like sensilla chaetica, sensilla basiconica, sensilla trichodea, branched processes, hair membrane plate sensilla and cuticular plate sensilla are present on the mouthparts of $A$. florea. These should make this organism an efficient forager, detector and collector. Sensilla chaetica on the prementum, galea, labial palps and the glossa can make the flow of liquid food to the buccal cavity more convenient. Sensilla basiconica found on the labial palps probably serve as thermoreceptors and hygroreceptor. Cuticular scales on the labial palps and hair membrane plate sensilla probably function in adjusting the segments of the organ and serve as mechanoreceptors.

\section{ACKNOWLEDGMENTS}

We thank Mrs. Kusum Lata, a project fellow under the project from the Ministry of Environment and Forests (MOEF) for providing material. The authors are very grateful to Dr Rajeev Patnaik, an expert in electron microscopy at the Department of Geology, Panjab University, Chandigarh.

Etude des pièces buccales d 'Apis florea (Hymenoptera : Apidae ) au microscope électronique à balayage

abeille / Inde / sensille / morphologie / ultrastructure / MEB

Eine Rasterelektonenmikroskopiestudie über die Mundwerkzeuge von Apis florea (Hymenoptera: Apidae )

Apis florea / Honigbiene / Rasterelektonenmikroskopie / Sensillen / Mundwerkzeuge

\section{REFERENCES}

Agren, L. (1977) Flagellar sensilla of some colletidae (Hymenoptera: Apoidea). Int. J. Insect Morphol. Embryol. 4, 137-146

Anudeep (2013) Morphometric and scanning electron microscopic studies on Apis dorsata F. in populations of North West India. Ph.D. Thesis, Panjab University, Chandigarh

Anudeep, Kumar, N.R. (2012) Biodiversity in Apis dorsata F.: SEM comparison of antenna from two different populations. Geobios, 39, 75-79

Awad, A.A., Moustafa, A.M., Abdel- Rahman, M.F., Sayed, R.Q. (2014) Influence of different statuses of honey bee queens, Apis mellifera L. on the ultrastructure of the flagella on (3-day old) workers. J. Open Entomol 8, 22-36

Bálint, Z., Vértes, Z., Kertész, K., Biró, L.P. (2004) Scanning electron microscopic investigations in butterfly wings: detecting scale micro- and nanomorphology and understanding their functions. Curr. Issues Multidisc. Microsc. Res. Educ. 3, 87-92

Crane, E. (1990) Managing other bees for honey production, bees and beekeeping science, practice and world resource, pp. 274-284. Cornell University, New York

Dietz, A., Humphreys, W.J. (1971) Scanning electron microscopic studies of antennal receptors of the worker honey bee, including sensilla campaniformia. Ann. Entomol. Soc. Am. 64, 919-25 
Erickson, E.H., Carlson, S.D., Stanley, D., Garment, M.B. (1986) A scanning electron microscope atlas of the honey bee. Iowa State University Press, Ames. 292 pp

Erickson, E.H., Carlson, S.D., Garmen, M.B. (2009) A scanning electron microscope atlas of the honey bee. $180 \mathrm{pp}$ http://www.ars.usda.gov/SP2UserFiles/Place/ 20220500/AtlasoftheHoneybee.pdf

Esslen, J., Kaissling, K.E. (1976) Zahl und Verteilung antennaler Sensillen bei der Honigbiene (Apis mellifera L.). Zoomorphology 83, 227-251

Fisher, R.L. (2010) Bee, Princeton Architectural Press (Number 2/11)

Free, J.B. (1981) Biology and behaviour of the honey bee Apis florea and possibilities for bee keeping. Bee World 62, 46-59

Free, J.B., Williams, I.H. (1979) Communication by pheromones and other means $\mathrm{n}$ Apis florea colonies. J. Apic. Res. 18, 16-25

Frisch, K.V. (1967) The dance language and orientation of bees. Harvard University Press, Cambridge. 566 pp

Goodman, L.J. (2003) Form and function in the honey bee. International Bee Research Asssociation, Cardiff. 220 pp

Gupta, M. (1992) Scanning electron microscopic studies of antennal sensilla of adult workers of Apis florea F. (Hymenopter: Apidae). Apidologie 23, 47-56

Hallberg, E., Hansson, B.S., Löfstedt, C. (2003) Sensilla and proprioreceptors. In: Kristensen, N.P. (ed.) Lepidoptera, moths and butterflies: morphology, physiology and development, vol. 2, pp. 267-288. Walter de Gruyter, Berlin

Hepburn, H.R., Hepburn, C. (2005) Bibliography of Apis florea. Apidologie 36, 377-378

Hölldobler, B., Wilson, E.O. (1990) The ants. Belknap Press of Harvard University, Cambridge

Hudson, A. (1970) Notes on the piercing mouthparts of three species of mosquitoes (Diptera: Culicidae) viewed with the scanning electron microscope. Can. Entomol. 102, 501-509

Johnson, B.R. (2010) Division of labor in honeybees: form, function, and proximate mechanisms. Behav. Ecol. Sociobiol. 64, 305-316

Kaissling, K.E., Renner, M. (1968) Antennale Rezeptoren für queen substance und sterzelduft bei der Honigbiene. Z. Vergl. Physiol. 59, 357-361

Kleineidam, C., Romani, R., Tautz, J., Isidoro, N. (2000) Ultrastructure and physiology of the $\mathrm{CO}_{2}$ sensitive sensillum ampullaceum in the leaf cutting ant Atta sexdens . Arthropod Struct. Dev. 29, 43-55

Kristoffersen, L., Hallberg, E., Wallen, R., Anderbrant, O. (2006) Sparse sensilla array on Trioza apicalis (Homoptera: Triozidae) antennae - an adaptation to high stimulus level? Arthropod Struct Development 35, 85-92

Kumar, N.R., Nayyar, K., Anudeep (2014) Biodiversity in cavity-nesting honey bees Apis cerana F. and Apis mellifera L. (Hymenoptera: Apidae): ultrastructure of mouth-parts. J Global Biosci 3, 787-791
Lacher, V. (1964) Elektrophysiologische Untersuchungen an einzelnen Rezeptoren für Geruch, Kohlendioxid, Luftfeuchtigkeit und Temperatur auf den Antennen der Arbeitsbiene und der Drohne (Apis mellifera). Z. Vergl. Physiol. 48, 587-623

Lacher, V., Schneider, D. (1963) Elektrophysiologischer Nachweis der Riechfunktion von Porenplatten (Sensilla placodea) auf den Antennen der Drohne und der Arbeitsbiene (Apis mellifica L). Z. Vergl. Physiol. 47, 274-278

Lindauer, M. (1952) Ein Beitrag zur Frage der Arbeitsteilung im Bienenstaat. Z. Vergl. Physiol. 34, 299-345

Merivee, E., Ploomi, A., Rahi, M., Luik, A., Sammelselg, V. (2000) Antennal sensilla of the ground beetle Bembidion lampros Hbst (Coleoptera, Carabidae). Acta Zool. 81, 339-350

Merivee, E., Ploomi, A., Rahi, M., Bresciani, J., Ravn, H.P., Luik, A., Sammelselg, V. (2002) Antennal sensilla of the ground beetle Bembidion properans Steph. (Coleoptera, Carabidae). Micron 33, 429-440

Michener, C.D. (1974) The social behaviour of the bees. Harvard University Press, Cambridge

Mujagic, S., Sarkander, J., Erber, B., Erber, J. (2010) Sucrose acceptance and different forms of associative learning of the honey bee (Apis mellifera L.) in the field and laboratory. Front. Behav. Neurosci. 4, 1-11

Nayyar, K. (2003) Honey bee diversity: scanning electron microscopic studies. M.Sc. dissertation, Panjab University, Chandigarh.

Okada, J., Toh, Y. (2000) The role of antennal hair plates in object guided tactile orientation of the cockroach (Periplaneta americana). J. Comp. Physiol. A. 186, 849-857

Okada, J., Toh, Y. (2001) Peripheral representation of antennal orientation by the scapal hair plate of the cockroach Periplaneta americana. J. Exp. Biol. 204, 4301-4309

Onagbola, E.O., Fadamiro, H.Y. (2008) Scanning electron microscopy studies of antennal sensilla of Pteromalus cerealellae (Hymenoptera: Pteromalidae). Micron 39, 526-535

Onagbola, E.O., Meyer, W.L., Boina, D.R., Stelinski, L.L. (2009) Morphological characterization of the antennal sensilla of the Asian citrus psyllid, Diaphorina citri Kuwayama (Hemiptera: Psyllidae), with reference to their probable functions. Micron 39, 1184-1191

Padilla, A.F., Da Silva, V.M.J., Campano Cabanes, F., Jimenez Vaquero, E., Flores Serrano, J.M., Puerta, P.F., Bustos, R.M. (2001) Discriminacion entre poblaciones de abejas (Apis mellifera L.) del suude Espana, Centro de Portugal of Madeira. Arch. Zootec. 50, 79-89

Page Jr., R.E., Linksvayer, T.A., Amdam, G.V. (2009) Social life from solitary regulatory networks: a paradigm for insect sociality. In: Gadau, J., Fewell, J. (eds.) Organization of insect societies: from genomes to socio-complexity, pp. 357-376. Harvard University Press, Cambridge 
Pe'rez-Gonza'lez, S., Zaballos, J.P. (2013) Antennal morphology of the endogean carabid genus Typhlocharis (Coleoptera: Carabidae: Anillini): description of sensilla and taxonomic implications. J. Morph. 7, 809-823

Rivera, A.J.R. (2009) Body size and the neural, cognitive and sensory basis of sociality in bees. Ph.D Thesis, University of Arizona

Sanchez, M.G.B. (2011) Taste perception in honey bees. Chem. Senses 2, 1-18

Scheiner, R., Erber, J. (2009) Sensory thresholds, learning and the division of foraging labor in the honey bee. In: Gadau, J., Fewell, J. (eds.) Organization of insect societies: from genomes to socio-complexity, pp. 335-356. Harvard University Press, Cambridge

Scheiner, R., Page, R.E., Erber, J. (2004) Sucrose responsiveness and behavioral plasticity in honey bees (Apis mellifera ). Apidologie 35, 133-142

Schneider, D. (1968) Basic problems of olfactory research. In: Tanyola CNT, (Eds). Theories of odour measurement. Necmi N. Tanyolac, U.K: pp. 201-211

Schneider, D., Steinbrecht, R.A. (1968) Checklist of insect olfactory sensilla. Symp. Zool. Soc. Lond. 23 , 279-297

Schneider, D., Lacher, V., Kaissling, K.E. (1964) Die Reaktionsweise und das Reaktionspektrum von Riechzellen bei Antheraea pernyi (Lepidoptera: Saturniidae). Z. Vergl. Physiol. 48, 632-662

Sharma, R. (2004) Biodiversity in honey bees: scanning electron microscopical analysis. M.Sc. Dissertation, Panjab University, Chandigarh

Slifer, E.H., Prestage, J.J., Beams, H.W. (1959) The chemoreceptors and other sense organs on the antennal flagellum of the grasshopper (Orthoptera: Acrididea). J. Morphol. 105, 145-191
Snodgrass, R.E. (1956) Anatomy of the honey bee Comstock publishing associates. Cornell University Press, Ithaca

Spaethe, J., Moser, W.H., Paulus, H.F. (2007) Increase of pollinator attraction by means of a visual signal in the sexually deceptive orchid, Ophrys heldreichii (Orchidaceae). Plant Syst. Evol. 264, 31-40

Steinbrecht, R.A. (1984) Chemo, hygro and thermoreceptors. In: Bereiter, A.G. Matoltsy, H.G. Richards, K.S. (Eds), Invertebrates: biology of the integument, vol. 1 Springer pp. 523-553

Suwannapong, G., Noiphrom, J., Benbow, M.E. (2012) Ultramorphology of antennal 416 sensilla in Thai single open nest honeybees (Hymenoptera: Apidae). J. Trop. Asian Entomol. 1, 1-12

Thurm, U. (1964) Mechanoreceptors in the cuticle of the honey bee: fine structure and stimulus mechanism. Science 45, 1063-1065

Vogel, R. (1921) Zur Kenntnis der Geruchsorgane der Wespen und Biene. Zool. Anz. 53, 20-28

Whitehead, A.T., Larsen, J. (1976) Ultrastructure of the contact chemoreceptors of Apis mellifera (Hymenoptera: Apidae). Int. J. Insect Morphol. Embryol. 5, 301-315

Wongsiri, S., Lekprayoon, C., Thapa, R., Thirakupt, K., Rinderer, T.E., Sylvester, H.A., Oldroyd, B.P., Booncham, U. (1996) Comparative biology of Apis andreniformis and Apis florea in Thailand. Bee World 77, 23-35

Zacharuk, R.Y. (1985) Antennae and sensilla. In: Kerkut, G.A., Gilbert, L.I. (eds.) Comprehensive insect physiology, biochemistry and pharmacology, vol. 6, pp. 169. Pergamon Press, Oxford 